\title{
BMJ Open Healthcare professionals' perceptions of learning communication in the healthcare workplace: an Australian interview study
}

\author{
Charlotte Denniston, ${ }^{1,2}$ Elizabeth K Molloy, ${ }^{2}$ Chee Yan Ting, ${ }^{3}$ Qi Fei Lin, ${ }^{3}$ \\ Charlotte E Rees ${ }^{1}$
}

To cite: Denniston C, Molloy EK, Ting CY, et al. Healthcare professionals' perceptions of learning communication in the healthcare workplace: an Australian interview study. BMJ Open 2019;9:e025445. doi:10.1136/ bmjopen-2018-025445

- Prepublication history for this paper is available online. To view these files, please visit the journal online (http://dx.doi. org/10.1136/bmjopen-2018025445).

Received 19 July 2018 Revised 19 October 2018 Accepted 12 December 2018

Check for updates

(C) Author(s) (or their employer(s)) 2019. Re-use permitted under CC BY-NC. No commercial re-use. See rights and permissions. Published by BMJ.

${ }^{1}$ Monash Centre for Scholarship in Health Education (MCSHE), Monash University, Clayton, Victoria, Australia

${ }^{2}$ Department of Medical Education, The University of Melbourne, Melbourne, Victoria, Australia

${ }^{3}$ Department of Physiotherapy, Monash University, Clayton, Victoria, Australia

Correspondence to Dr Charlotte Denniston; charlotte.denniston@unimelb. edu.au

\section{ABSTRACT}

Objectives The literature focuses on teaching communication skills in the 'classroom', with less focus on how such skills are informally learnt in the healthcare workplace. We grouped healthcare work based on the cure:care continuum to explore communication approaches based on work activities. This study asks: 1) How do healthcare professionals believe they learn communication in the workplace? 2) What are the differences (if any) across the 'type of work' as represented by the cure:care continuum?

Design This qualitative study used semi-structured individual interviews.

Setting Community care and acute hospitals in Australia (Victoria and New South Wales).

Participants Twenty qualified healthcare professionals (medicine $n=4$, nursing $n=3$, allied health $n=13$ ) from various clinical specialties (eg, acute, rehabilitation, surgery, palliative care) participated.

Methods Data were analysed using framework analysis, which involved the development of a thematic coding framework. Findings were mapped to participants' descriptions of work using the cure:care continuum. Results Three themes were identified that varied across the cure:care continuum: professional discourse-tying communication approaches to work activities; personal identities - the influence of personal identities on healthcare communication and role modelling - the influence of others in the socially bound context of healthcare work.

Conclusions This study highlights the influence of professional, personal and social factors on the learning of healthcare communication in the workplace. Our study illuminates differences in communication practice related to work activities, as conceptualised by the cure:care continuum. The results call for further examination of the 'nature' of work activities and the concomitant influence on developing healthcare communication.

\section{INTRODUCTION}

In 1927, Frances Peabody proposed that 'the secret of the care of the patient is in caring for the patient'. ${ }^{1}$ Communication with patients is the key means by which this caring
Strengths and limitations of this study

- Healthcare professionals from a range of clinical backgrounds and contexts shared their beliefs about healthcare communication practice, thus enhancing the transferability of the findings.

- The novel use of the cure:care continuum helped to provide a framework for exploring healthcare communication in the context of healthcare work-related activities.

- Despite the clinical background of the research team being relatively homogenous, transparent discussion and iterative data analysis reassured us that multiple interpretations had been considered.

- Participant gender is relatively homogenous, mostly female, which makes study findings more transferable to female healthcare professionals than males.

relationship is built and maintained. Additionally, effective patient-healthcare professional (HCP) communication has implications for the effective delivery of healthcare, information exchange and quality decision-making. ${ }^{2}$ As such, communication skills in health professional education features as a popular topic for study. Although literature exploring communication skills teaching is vast and represents multiple professions, it has often focused on doctor-patient communication. ${ }^{34}$ It is however important to consider how communication and patient care is enacted across settings, professions and specialties within the healthcare system. After all, care of the patient is the primary goal of work in all areas of healthcare, but what that looks like in different contexts is likely to differ. The different properties of healthcare work, and how these influence communication practice, still remains relatively unexplored.

Teaching versus learning communication In healthcare, communication is central to interactions between HCP, patients, families 
and colleagues. There are a range of educational initiatives designed to develop skills for communicating with others in the workplace, including small group tutorials, scenarios using simulated patients, reflection on video-recordings and role-plays. ${ }^{5} 6$ These teaching approaches are often characteristic of what Billett calls 'schooling' or taught experiences in/by educational institutions. ${ }^{7}$ Much of the literature exploring communication skills teaching investigates the effectiveness of this formal 'schooling', with fewer studies examining how these skills are perceived to be informally learnt in the complex workplace learning environment. It is important to note that the focus on the 'schooling' of these skills is for good reason. We know that skilled communication does not occur spontaneously and the 'training' of communication skills needs to be successfully delivered and studied. ${ }^{8}$ However, a significant challenge facing communication skills educators and researchers is the transfer of skills learnt in the classroom to the workplace. ${ }^{9}$

\section{Learning communication in the workplace}

Although studies have investigated medical student or junior doctors' experiences of learning communication skills in the workplace, ${ }^{10-12}$ few have explored experienced HCPs. A recent study by van den Eertwegh et $a l^{13}$ explored communication skills learning in the workplace from the perspective of qualified general practitioners (GPs). The authors observed practice and interviewed 12 GPs using videos of consultations as interview prompts. Their findings informed the development of a fivephase communication learning process that included being confronted and becoming conscious of one's own behaviour, searching for an alternate behaviour and then personalising and integrating the new behaviour. ${ }^{13}$ Mendick et $a l^{4}$ analysed 19 interviews from 8 breast surgeons and explored how these surgeons thought desirable communication arose in their practice. Their findings emphasised workplace learning of communication as a more authentic way of learning, and that the learning of discrete communication skills in formal learning was artificial. ${ }^{4}$ However, these studies, and an earlier study from van den Eertwegh et $a l,{ }^{14}$ have taken a uniprofessional approach to exploring workplace learning of communication and in line with much of the communication skills literature, have focused on the medical profession, and the communicative encounter of doctor-patient, rather than broader application of colleague to colleague, or team-based communication.

Researchers of workplace learning make claims that each professional engages individually and collectively in a variety of goal-directed activities, including communication, in their completion of work. ${ }^{15}$ Learning can occur both with (explicit) and without (implicit) conscious awareness as workers engage in these work-related activities. ${ }^{716}$ Further exploration of how communication skills are learnt in the workplace needs to account for the diversity of activities undertaken by a range of healthcare professions, taking into consideration the different situations, cultures, values and ways of being that may influence learning.

\section{The cure:care continuum}

One way of exploring these differences between HCPs is to consider how HCPs and their associated work activities, exist along a continuum. ${ }^{17} 18$ Descriptions of a cure:care continuum have previously been reported in the nursing and healthcare management literature, and we employ a simplified version of this continuum in our study as one way to conceptualise work-related activities and HCPs' roles. According to Glouberman and Mintzberg, ${ }^{18}$ at one extreme of this continuum, a HCP's work is thought to be associated with 'curing'. A 'curing' healthcare activity is proposed as requiring an intrusive action such as incursion (eg, surgical incision), or ingestion (eg, consuming of medications) as a means of curing disease. At the contrasting end of the continuum, an intervention is described as 'caring'. At the 'caring' end of the continuum, activities are interpretive in approach and can include touch (eg, manipulation) and talk (eg, mediation). This division between cure and care has been problematised as both ends of this continuum signify noble and necessary endeavours in patient care. However, these groupings may be seen as one way to explore how healthcare roles, work activities or communication are understood across professions. ${ }^{17}$

\section{Study aims and research questions}

The research presented here aims to further explore how communication skills are perceived to be learnt relative to work-related activities and context. Therefore, this study will address the following research questions:

RQ1: How do healthcare professionals believe they learn communication in the workplace?

RQ2: What are the differences (if any) across the "types of work' as represented by the cure:care continuum?

\section{METHODS \\ Design}

This qualitative study is underpinned by social constructionism, which supports looking beyond the individual role (ie, professional label) and promotes exploring the world constructed by an individual in and through their social interactions with others. ${ }^{19}$ Aligning with social constructionism, this study chose an interpretivist lens, acknowledging there can be multiple interpretations of reality. ${ }^{20}$ Informed by these notions, this research explores participants' interpretations of learning communication in the social context of healthcare work. A semi-structured individual interview design was chosen. This approach was deemed appropriate for exploring participants' interpretations and perceptions of learning communication in the workplace. An interview guide was used to inform the interaction and was piloted for refinement prior to data collection. $^{21}$ 


\section{Participants and sampling}

Twenty senior HCPs took part in this study (female: $n=14$; male $n=6$ ). Participants worked in Australia (Victoria: $\mathrm{n}=17$, New South Wales: $\mathrm{n}=3$ ), and were born primarily in Australia with English-speaking backgrounds. After ethical approval, purposive sampling, via email invitation through the clinical and/or academic networks of the first and second authors, targeted characteristics including profession (eg, medicine, nursing and allied health) and setting (eg, acute, rehabilitation, surgery, palliative care). Invited participants must have had 10 or more years' experience as a way to target those with opportunity to develop expertise in their area of practice and to enable the exploration of influences and shifts in their communication practices in regard to their working careers. $^{22}$

Sampling in this study was guided by the principles of information power. ${ }^{23}$ Malterud et al argued that a broad aim and cross-case (between participant) analysis, which is characteristic of this study, indicates the need for a larger sample size to maintain information power. ${ }^{23}$ Conversely, a high sample specificity, the application of theory in planning and analysis (eg, social constructionism, cure:care continuum, etc) and a strong dialogue within all the interviews indicates a greater information power and therefore a smaller sample needed. In sum, we believe our sample size of 20 was sufficient to address our research questions.

\section{Data collection}

The primary researcher (CD) conducted all interviews between November 2014 and March 2016. With informed consent, 15 interviews were completed face-to-face and 5 by telephone. The average interview length was $59 \mathrm{~min}$ (range 25-102 min; total $1182 \mathrm{~min}$ ). All interviews were audio-recorded, transcribed verbatim and anonymised.

Participants were asked to share demographic information and a brief biography of their clinical work. Participants were prompted to share stories of communication interactions they had experienced to explore their interpretations of what constitutes skilled communication (ie, can you discuss a healthcare interaction you have experienced, been a part of, where communication was performed well/poorly?). Participants were invited to elaborate on the characteristics of the communication in these examples. Participants were asked to reflect on their own communication skills over time, from prequalification to present (ie, in what ways (if any) do you think your communication practice with patients has shifted with experience? How did you learn that? How does (if at all) your workplace influence your clinical communication?). While we collected participants' perspectives of learning communication in the workplace, we did not collect specific information about their learning from formal communication skills activities, nor did we collect information specifically related to their perceived positions on the cure:care continuum. Closed questions were used to clarify details throughout. After each interview, the primary researcher (CD) completed a 'contact summary form' reflecting on immediate impressions. ${ }^{21}$

\section{Data analysis}

Data analysis was guided by framework analysis ${ }^{24}$ with the following five defined steps. Step 1 involved the process of familiarisation, with the core research team (CD, EM, CER) individually listening to and analysing the first six transcripts. Step 2 involved identifying the thematic coding framework where researchers CD, CER and EM identified key themes from the data and, through an iterative process of discussion and revision, a thematic coding framework was developed. Step 3 was characterised by indexing; the coding framework was uploaded to NVivo and coding, or 'indexing,' was completed on all transcripts. CD coded the entire data set with $75 \%$ of transcripts checked by at least one additional member of the research team (CYT or QFL). NVivo was used to facilitate this process of team-based coding. During this analysis, regular team communication continued, with new themes or concerns about existing themes discussed and disagreements resolved. In step 4, once coded, data were grouped under themes, called charting. These themes were then analysed relative to participants' characteristics, with similarities and differences documented (or 'charted'). Finally, step 5 constituted mapping and interpretation, whereby data were further interpreted with respect to the cure:care continuum. ${ }^{18}$ The matching of participants to anchors at either end of the continuum occurred as an interpretative process undertaken by the research team during the data analysis stage. Assignment of participants to points on the continuum was relative to the current 'work' the participants described in their interviews rather than their professional membership or previous working contexts.

\section{Patient and public involvement}

Given our focus on HCPs' perceptions in this current study, patients were not specifically involved in the design, data collection or analysis of this study.

\section{RESULTS}

In exploring interpretations of learning communication in the workplace, three key themes were identified: professional discourse, personal identities and role modelling. These themes are not mutually exclusive and therefore some illustrative quotes run across multiple themes. All themes address RQ1 and are elaborated here to also address RQ2. Figure 1 presents a summary of participant details as per the cure:care continuum. Quotes within the text illustrate the key themes and include the following transcription notations: $()=$. micropause, -=running on talk, ... =quote abridged for presentation and (text)=detail added by research team for clarity. 


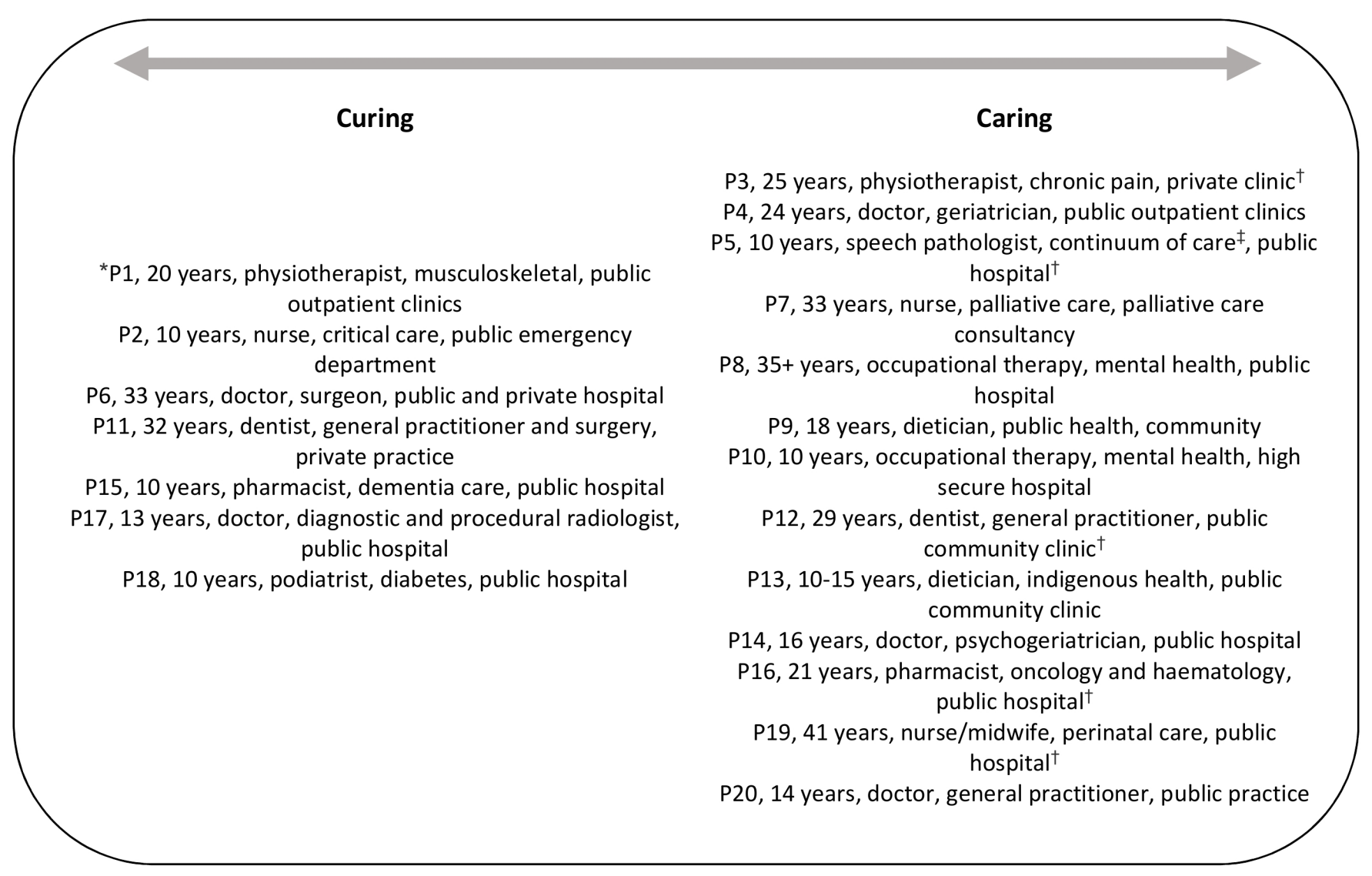

Figure 1 Participant continuum. *P1=participant 1; years of experience (years since graduating from first healthcare degree at time of interview); participants are described according to their construction of their clinical identity (including profession, specialty and clinical setting). †These participants had shared narratives about a significant shift in their own communication practice in the workplace, often punctuated by a shift in their identities from 'curers' to 'carers'. ‡Continuum of care refers to a model of care where one healthcare professional (from any profession) sees a patient from admission at the emergency department throughout their inpatient stay.

\section{Professional discourse}

Participants nearly always provided examples of practitioner-patient communication, rather than examples of dyadic peer-to-peer communication, or team-based interactions when describing their communication practice. Participants reported stereotypical communication within their own work activities (ie, patient care) and a recognisable communication in others. This has been described elsewhere as professional discourse: the language used by professionals to get something done in the workplace. ${ }^{25}$ Furthermore, the cure:care continuum was found to influence the professional discourse reported, and in turn influenced how communication was learnt in that context. For example, a 'curing' discourse was characterised by concise communication that was 'to the point' and addressed the needs of the clinician in their 'curing' role. In this group, communication was conceived as shortterm interactions that facilitated or formed the backdrop to the 'real work':

... cause you don't really interact with the patients. So, I do a lot of procedures... So, I have a very brief period of interaction usually when they turn up, then I have to consent them in some form and get them on side (P17, 13 years, doctor, diagnostic and procedural radiologist, public hospital, cure)

Participants commented that the emphasis in this 'curing' environment was speed, throughput and at times the 'patient could be left behind'. Settings such as this were described as emergency departments and certain wards in acute hospitals. In the next quote, a speech pathologist speaks of her previous experience in a 'curing' context and the influence on communication expectations:

It (the medical model) was fast paced, it was snappy (laughs). So, I guess if you conceptualise communication within that, there is a model of communication that fits that, that it is very focused on the meeting your requirements... I guess part of it was that I was very clinician-driven "What do I need out of this interaction? I need to get this information. I need to share this information" you know? (P5, 10 years, speech pathologist, continuum of care, public hospital, care)

At the opposite end of the continuum, a 'caring' professional discourse was characterised by deeper interactions and collaborative relationships. The focus of this group's 
discourse was attending to, or an orientation to, the patient's perspective:

My clinical work is... what I find a lot of my patients need is someone to sit with them and resist the urge to do something but often just to sit there, and listen to their story, and often respond to their emotional situation, and often contain their anxiety. But that's a very major part of my job (P14, 16 years, doctor, psychogeriatrician, public hospital, care)

Some participants had worked across multiple settings throughout their careers and described different discourses relative to their different work contexts. This suggested that the professional discourse, or communication relative to work activities, was more context-dependent than profession-dependent and this influenced the communication that was learnt and practised. For example, the next quote is from an emergency nurse (curing) who reflected on previous experiences working in a haematology ward (caring):

You have time for your patients, which you don'tyou just don't sometimes in Emergency so it's (.) and by then, they're usually settled in. They're stabilised as well so it's a completely different scenario up there (on the haematology ward). You can give them the TLC (tender loving care) that you sometimes can't give them in Emergency so you are able to communicate. You're actually able to sit down and have a conversation (P2, 10 years, nurse, critical care, public emergency department, cure)

\section{Personal identities}

Participants reported that their personal identities (eg, age, parent, daughter, etc) influenced healthcare communication. Indeed, participants' experiences of being carers, children, parents or friends seemed to influence their professional communication practices. For example, participants at the 'caring' end of the continuum seemed to be more likely to reflect on this intersection between their personal identities and communication practices as part of their interviews than those at the 'curing' end, as illustrated in the next quote:

I was close enough to my dad's experience (as a patient) to be able to remember the things that, you know, the people who didn't talk or the silly things they'd done. And that-that made a big impression on me, I will say (P19, 41 years, nurse/midwife, perinatal care, public hospital, care)

Participants also reflected on the significance of being patients themselves. These authentic personal experiences reportedly made participants better communicators:

It would be great if every person had to become a patient. That would be great. You learn a lot being a patient, um (.) and I think that's important... and I think they (clinicians) need to think back about how they wanted to be treated, how they wanted to be listened (to) and, you know, important things got across (P1, 20 years, physiotherapist, musculoskeletal, public outpatient clinics, cure)

Participants across the continuum also spoke of how 'growing up' influenced their approaches to communication. This notion of change in communication practice with age, related to both participants' reflections on themselves and their observations of junior HCPs, which reminded them of their own starting points and subsequent shifts in practice. Participants from the caring end of the continuum spoke about developing compassion and an 'appreciation of humanity' with increasing age. This aspect of practice was reported as sometimes being missed by junior HCPs because of their preoccupation with the 'technical' components of work activities and due to their limited life experiences:

They've (junior medical trainees) just experienced so little in life, as I had, at that age... It's that they tell people things in a casual fashion. They just (.) don't (.) feel the impact and just how big this news is... If I had to tell somebody something shocking, you realise that you've just released a tsunami on somebody. and I think now I've, you know I'm a bit older, that I've had friends who've had terrible diagnoses... I know that when I talk to people-I-ah, you do, you carry that in your heart and you know what you're doing. So, I think that makes a big difference (P4, 24 years, doctor, geriatrician, public outpatient clinics, care)

Participants across the healthcare continuum reported that growing older, or having 'been around the block', meant that they had learnt to be more aware of themselves and how their thoughts, emotions and circumstances may have influenced their communication practice. Despite participants at the 'caring' end of the continuum being more likely to reflect on the influence of personal identities on their communication in their interviews, participants did not volunteer in their interviews how their personal identities may have changed (or not) as they moved across caring and curing contexts.

\section{Role modelling}

When asked about influences on their communication skill development, most participants did not report that 'schooling' (ie, taught experiences in/by educational institutions) served as inflection points for their understanding or practice of communication. Rather, communication skills were reportedly learnt through observing and modelling others. Those towards the cure end of the continuum were likely drawn to role models who held senior clinical or management positions, generally from the same profession as the participants. The quote presented next refers to a dentist's experience of observing senior dentists during training:

I had no formal training... apart from what we saw and heard in the demonstration clinics... the people 
holding those were other similarly ungifted, older dentists, or even sometimes people that's a couple of years older than us (P11, 32 years, dentist, general practitioner and surgery, private practice, cure)

Interestingly, participants whose work practices were conceptualised towards the care end of the continuum referred to role models who were of any, often different, professions. These role models were not necessarily linked to formal mentoring relationships, or statusbound along reporting lines, but were instead situated in daily practice, as illustrated in the following quote:

I learnt a lot of my communication and what patients expect and how they communicate back in my setting from (.) I guess that was the day centre nurses and... I say that all the time. I mean it was lucky I had the day centre nurses 'cause that's where I learnt everything (P16, 21 years, pharmacist, oncology and haematology, public hospital, care)

Participants reported that what is espoused as good communication in training is not guaranteed to be observed in practice. Typically, observing someone with desired communication skills was 'serendipitous' rather than facilitated through formal relationships such as direct reports or assigned mentors. Participants reported that observing others was a basis for reflection on one's own performance and therefore a strong stimulus for learning. However, once qualified, observing others was reported as 'rare'.

\section{Interactions between themes}

As illustrated in the quotes above, these data suggest an interplay between themes. This was evidenced by the intersection of professional discourse and personal identities, although arguably, the professional discourses described were socially learnt via role modelling. Participants shared reflections on their own preferences for communicating with others and how aligning personal and professional identities impacted career decision-making and evolving communication practice. The next quote is from a GP who reflected on personal communication preference and choice of a medical specialty orientated to the 'care' end of the continuum:

I think that's why it (General Practice) appealed to me and I guess (.) in some ways, that's why psychiatry appealed to me uhm (.) as well. And that's using your communication skills in a slightly different-different way uhm uh (.) but uhm (.) you know, I-I can see certainly the areas that-that didn't appeal to me in medicine, like surgery and like uhm (.) you know, some of the areas of physician, but probably mainly sort of surgery and uhm (.) radiology and pathology and those areas-where you're not talking to (the patient) that just didn't interest me at all, so, yeah, absolutely, it was a big part of why I probably chose general practice (P20, 14 years, doctor, general practitioner, public practice, care)
Although this participant reported alignment, some participants revealed incongruences between the professional discourse characteristic of their work activities and their own personal beliefs about 'good' communication. Despite clinicians themselves recognising that a 'care' orientation aligned with their personal identities, this approach was described as low priority in 'cure' settings. For example, the next quote, from a senior dentist, describes the personal and work-related influences on communication practice as discordant:

So, now, I'm a real less-is-more clinician... You know, most of my appointments are talking, less time doing. Uhm (.) and I think that that gives a type of practice uhm (.) that is very valued by the client. But- howhowever, market forces are that it's not actually very valued in terms of a health rebating item thing, you know? So, you know, like a lot of health professions we're-we're rebated via item number. By a 'doing' of something to people uhm (.) and so lots of things get done perhaps maybe unnecessarily (P12, 29 years, dentist, general practitioner, public community clinic, care)

Participants reported that the focus on 'targets' from a managerial level (such as daily patient statistics and medical rebates) or expectations to intervene (such as prescribing drugs or 'laying on of the hands') were at the expense of a 'care' professional discourse.

\section{DISCUSSION}

\section{Summary of findings}

This study has reported the influence of professional, personal and social factors on the development of healthcare communication in the workplace. Of note was that almost exclusively participants' views and descriptions of 'good communication' and learning to communicate, were confined to exchanges between patients and practitioners (rather than collegial communication). In these results, we did not see discourses specifically related to professional membership (ie, medicine, nursing or allied health) as we had originally expected. Instead, in relation to our first research question, participants reported that their communication related to work activities (ie, professional discourses) and that their communication practice was influenced by their own personal identities and exposure to role models in the workplace. With respect to our second research question, where we drew on the cure:care continuum in our analysis, we found intriguing differences in our identified themes as per the different types of work done by participants. Indeed, the unique contribution of this study to current communication research is how these findings were constructed with respect to the cure:care continuum (table 1).

The cure:care continuum in healthcare work: what is the impact on communication practice?

HCPs in this study reported that they developed their individual communication practice through interactions 
Table 1 Summary of findings as sensitised by the cure:care continuum

\begin{tabular}{|c|c|c|}
\hline & Cure & Care \\
\hline $\begin{array}{l}\text { Professional } \\
\text { discourse }\end{array}$ & $\begin{array}{l}\text { Communication seen } \\
\text { as the means to an } \\
\text { end, clinician-driven, } \\
\text { transactional }\end{array}$ & $\begin{array}{l}\text { Communication } \\
\text { seen as the practice } \\
\text { instrument, patient- } \\
\text { centred, relational }\end{array}$ \\
\hline $\begin{array}{l}\text { Personal } \\
\text { identities }\end{array}$ & $\begin{array}{l}\text { Less likely to } \\
\text { reflect on personal } \\
\text { identities and their } \\
\text { influence on practice }\end{array}$ & $\begin{array}{l}\text { Reflected on how } \\
\text { their own identities } \\
\text { influenced their } \\
\text { communication } \\
\text { practice }\end{array}$ \\
\hline Role modelling & $\begin{array}{l}\text { Often those who } \\
\text { were senior to them } \\
\text { and within the same } \\
\text { profession (hierarchy } \\
\text { and reporting lines } \\
\text { key) }\end{array}$ & $\begin{array}{l}\text { Often from different } \\
\text { professions } \\
\text { (collaborative) } \\
\text { and arising from } \\
\text { informal interactions } \\
\text { rather than formal } \\
\text { relationships }\end{array}$ \\
\hline
\end{tabular}

in the workplace. Participants were not asked, and did not volunteer, information about formal teaching of communication and we surmise that the lack of volunteered information may be due to the seniority of this sample. It is likely that communication skills teaching may not have been included in the preregistration training of these HCPs (ie, $>10$ years ago) and postregistration opportunities for formally learning communication skills may not have been readily available. Or perhaps, participants felt workplace learning of communication skills was more authentic than formal teaching, similar to the breast surgeons in the study by Mendick et $a l^{4}{ }^{4}$ Regardless, this group of participants perceived the workplace as a significant influence on their healthcare communication practice, which is consistent with wider workplace learning literature.

According to workplace learning scholars, learning is considered as a process through which workers interact with social experiences they encounter while doing work. ${ }^{1526}$ The influence of work-related goals and activities have previously been reported as a factor influencing communication practice in healthcare. Thomson et al explored new graduates' perceptions of interprofessional teamwork and communication and found that work-related goals influenced HCPs communication. However, they did not explore graduates' perceptions of how those skills were learnt. Recently, Mendick et at ${ }^{4}$ explored breast surgeons' perceptions, and like our results found that goals for patient care (ie, work-related goals), watching others and personal style influenced surgeons' communication with patients. ${ }^{4}$

In their integrative framework, Glouberman and Mintzberg $^{18}$ reported that a 'cure interaction' was characterised by short scheduled bursts, and a 'care interaction' was constituted through continuous and collaborative interactions. Our findings confirm but extend this (table 1). Our study found that 'curing' communication was conceptualised as clinician-driven, thus logically following temporal features by Glouberman and Mintzberg ${ }^{18}$ and the time demands of clinicians. 'Caring' communication, on the other hand, was described as patient-centred in our study, characterised by a collaborative and continuous approach. This makes sense when explored with respect to the roots of patient-centred care, that is, primary care medicine, arguably a 'caring' discipline. ${ }^{28}$ We also found that the professional discourses aligned with the cure:care continuum were influenced by context, more so than professional discipline or the clinician themselves, which is an extension of previous interpretations of this continuum. $^{17}$

We found that participants whose work was described at the 'care' end of the continuum were more likely to reflect on personal identities and the psychosocial impact of self on communication practice. This link has been shown elsewhere with preferences for medical specialties, communication skills practice and reflection in the clinical context. ${ }^{111429}$ This alignment with the 'care' end of the continuum may also be related to 'caring' professions privileging reflection and social sciences more than those with a 'curing' orientation. ${ }^{30} 31$

Our findings also identify the influence of role modelling in developing communication, which in health professions education is not new. ${ }^{1432} \mathrm{~A}$ unique finding from our study, however, was differences in role model selection. Participants on the 'care' end appeared to choose role models from any profession or specialty with attributes they desired or aligned with. This may be explained by the more collaborative models of healthcare typified by 'care' type work or by the shared leadership characterised by a 'care' organisational structure. ${ }^{183}$ Conversely, role model selection at the 'cure' end seemed to be status-related, within the same profession. ${ }^{34}$ The organisational structure of this end of the continuum has been described as hierarchical, ${ }^{18} 35$ and this may partly explain the social influences on our participants' role model selection and the influence of seniority for those conceptualised at the 'cure' end. While current literature tends to concentrate on the characteristics of role models from within the same profession as the learner (ie, medical student and physicians), ${ }^{32}$ there is little literature exploring the influence of interprofessional role modelling in the health professions (for a recent example see Rees $e t a \rho^{66}$ ), particularly in regard to communication skill development.

\section{Methodological strengths and challenges}

We believe the professional diversity in our sample (ie, across the continuum) is a strength, as many previous explorations of this topic have limited the focus to one profession alone (often, medicine). However, we acknowledge that the sample does not represent the full diversity of HCPs and contexts. A limitation of this study is the relative homogeneity of participant gender, mostly female, which has repercussions for the application of findings to male HCPs. The homogeneity of the research team is also a limitation (4/5 researchers 
were or are clinical physiotherapists), meaning that the professional discourses brought to bear on the data were narrower than ideal. However, transparent data analysis and discussion within the research team reassured us that multiple interpretations of the data had been considered. Finally, our novel use of the cure:care continuum in this study could be seen as both a strength and a challenge. For example, although often used to make incorrect, and unfavourable, judgements about people, some scholars suggest that stereotypes, such as those presented in the continuum used here, are socially constructed and can offer useful ways of grouping people because groups of people behave in predictable ways. ${ }^{37}$ However, we do not make value judgements about the professional discourse of either group on the continuum, nor do we suggest the opposite end of the continuum is the inverse of the other (ie, curers do not care, etc). Instead, we feel that by using this conceptual framework, this paper may challenge preconceptions about professions by highlighting the relationship between professional discourse, personal identities, role modelling and a professional's engagement in certain work activities, which invite or constrain certain communication approaches. However, because this continuum was not employed at the point of study recruitment or data collection, we could not explore participants' own perceptions of the nuances of the continuum and the interplay with professional discourse, personal identities and role modelling over their working careers.

\section{Implications for educational practice}

Despite some methodological challenges, the results of this study have a number of implications for educational practice. In preparation for workplace learning, and complementary to formal communication skills teaching, healthcare learners could be exposed to professional discourses from across the cure:care continuum prior to the workplace to better prepare them for the diversity of communication practices they will encounter. Priming learners to recognise that workplace communication practices will differ with respect to work-related activities (across the curing:caring continuum) would be valuable. So too would overt discussions about discordance between practice models introduced at university, and those witnessed within the workplace in order to discourage unreflective imitation. ${ }^{163438}$ Building on this, any communication interaction in the context of clinical work could provide an opportunity for reactive learning where a critically aware learner (of any level) could be encouraged to observe practice and determine how it aligns with their own personal understandings of 'good' communication practice. ${ }^{16263439}$ This reflective imitation does not require learners to observe good practice while in the workplace, which was a challenge encountered by participants in this study and others. ${ }^{26} 3234$ Additionally, the influence of personal identities on communication practice, as highlighted in our results, may prompt educators to consider reflection on personal identities as a component of future communication curriculum design. Currently, perceptual skills such as this type of self-reflection are under-represented in communication education. ${ }^{3}$

\section{Implications for further research}

Learning communication in the healthcare workplace may be more contextually bound than previously surmised. Aligning with the workplace learning literature, our findings have supported notions that personal and social factors influence learning throughout working lives and that professional work activities intersect to provide a context for learning communication in the workplace. ${ }^{715}$ This relationship warrants further exploration. Cruess et $a l^{39}$ and Jarvis-Selinger et $a l^{40}$ have explored the influence of personal identities, role modelling, professional environment and work activities on socialisation and the development of professional identities. However, exploring the intersection of these influences with respect to communication may offer avenues for further research. Qualitative research techniques such as longitudinal audio diaries or narrative analysis could be used as methods to explore individuals' perceptions of the cure:care continuum and how it may interplay with personal identity formation and communication practice in the workplace over time. Additionally, ethnographic studies exploring communication skills in different contexts could more accurately explore implicit and explicit learning of communication and could investigate the impact of professional membership, role models or work-related activities on communication practice and development.

We propose that the findings presented here can be used to complement the current 'schooling' of communication skills in health professions education, as well as prompt meaningful future discussions about the work activities that HCPs do, and the influence these contextual factors may have on healthcare communication and the care of the patient.

Acknowledgements The authors would like to thank Professor Jennifer Keating for her contribution to the design of the study and Reihaneh Ferooz for her contribution to data analysis. The authors would also like to thank the participants for contributing their time and experiences to this research. CD would like to thank the Australian National Health and Medical Research Council Post Graduate Scholarship, which supported the completion of this research.

Contributors CD, EKM and CER designed the study. CD, EKM and CER led the data analysis with contribution from CYT and QFL. CD produced the original draft of the manuscript. All authors critically revised the manuscript for intellectual content and approved the final submission.

Funding The authors have not declared a specific grant for this research from any funding agency in the public, commercial or not-for-profit sectors.

Competing interests None declared.

Patient consent for publication Not required.

Provenance and peer review Not commissioned; externally peer reviewed.

Data sharing statement No additional data are available.

Open access This is an open access article distributed in accordance with the Creative Commons Attribution Non Commercial (CC BY-NC 4.0) license, which permits others to distribute, remix, adapt, build upon this work non-commercially, and license their derivative works on different terms, provided the original work is properly cited, appropriate credit is given, any changes made indicated, and the use is non-commercial. See: http://creativecommons.org/licenses/by-nc/4.0/. 


\section{REFERENCES}

1. Peabody FW. The care of the patient. JAMA 1927;88:877-82.

2. Street RL, De Haes HC. Designing a curriculum for communication skills training from a theory and evidence-based perspective. Patient Educ Couns 2013;93:27-33.

3. Denniston C, Molloy E, Nestel D, et al. Learning outcomes for communication skills across the health professions: a systematic literature review and qualitative synthesis. BMJ Open 2017;7:e014570.

4. Mendick N, Young B, Holcombe C, et al. How do surgeons think they learn about communication? A qualitative study. Med Educ 2015;49:408-16.

5. Moore PM, Rivera Mercado S, Grez Artigues M, et al. Communication skills training for healthcare professionals working with people who have cancer. Cochrane Database Syst Rev 2013;3:CD003751.

6. Wouda JC, van de Wiel HB. Education in patient-physician communication: how to improve effectiveness? Patient Educ Couns 2013;90:46-53.

7. Billett S. Learning through health care work: premises, contributions and practices. Med Educ 2016;50:124-31.

8. Aspegren K, Lønberg-Madsen P. Which basic communication skills in medicine are learnt spontaneously and which need to be taught and trained? Med Teach 2005;27:539-43.

9. van den Eertwegh V, van Dulmen S, van Dalen J, et al. Learning in context: identifying gaps in research on the transfer of medical communication skills to the clinical workplace. Patient Educ Couns 2013;90:184-92.

10. Bombeke K, Symons L, Vermeire E, et al. Patient-centredness from education to practice: the 'lived' impact of communication skills training. Med Teach 2012;34:e338-48.

11. Bombeke K, Symons L, Debaene L, et al. Help, I'm losing patientcentredness! experiences of medical students and their teachers. Med Educ 2010;44:662-73.

12. Malhotra A, Gregory I, Darvill E, et al. Mind the gap: Learners' perspectives on what they learn in communication compared to how they and others behave in the real world. Patient Educ Couns 2009;76:385-90.

13. van den Eertwegh V, van der Vleuten $C$, Stalmeijer R, et al. Exploring residents' communication learning process in the workplace: a fivephase model. PLoS One 2015;10.

14. van den Eertwegh V, van Dalen J, van Dulmen S, et al. Residents' perceived barriers to communication skills learning: comparing two medical working contexts in postgraduate training. Patient Educ Couns 2014;95:91-7.

15. Billett S. Learning throughout working life: a relational interdependence between personal and social agency. Brit $J$ of Educ Stud 2008;56:39-58.

16. Eraut M. Non-formal learning and tacit knowledge in professional work. Br J Educ Psychol 2000;70:113-36.

17. Baumann AO, Deber RB, Silverman BE, et al. Who cares? Who cures? The ongoing debate in the provision of health care. J Adv Nurs 1998;28:1040-5.

18. Glouberman S, Mintzberg H. Managing the care of health and the cure of disease-Part I: Differentiation. Health Care Manage Rev 2001;26:56-69.

19. Burr V. What is social constructionism? Burr V, ed. Social constructionism. 3rd edn: Taylor and Francis, 2015.
20. Bunniss S, Kelly DR. Research paradigms in medical education research. Med Educ 2010;44:358-66.

21. Patton MQ. Qualitative research and evaluation methods. 3rd edn. California: Thousand OaksSage Publications, 2002.

22. Ericsson KA. Deliberate practice and the acquisition and maintenance of expert performance in medicine and related domains. Acad Med 2004;79:S70-81.

23. Malterud K, Siersma VD, Guassora AD. Sample size in qualitative interview studies: guided by information power. Qual Health Res 2015;2660.

24. Ritchie J, Spencer L. Qualitative data analysis for applied policy research. In: Bryman A, Burgess R, eds. Analysing qualitative data. London: Routledge, 1994.

25. Kong K. Introduction. Professional Discourse. Cambridge England: Cambridge University Press, 2014.

26. Watling $\mathrm{C}$, Driessen $\mathrm{E}$, van der Vleuten $\mathrm{CP}$, et al. Learning from clinical work: the roles of learning cues and credibility judgements. Med Educ 2012;46:192-200.

27. Thomson K, Outram S, Gilligan C, et al. Interprofessional experiences of recent healthcare graduates: a social psychology perspective on the barriers to effective communication, teamwork, and patientcentred care. J Interprof Care 2015;29:634-40.

28. Mead N, Bower P. Patient-centredness: a conceptual framework and review of the empirical literature. Soc Sci Med 2000;51:1087-110.

29. Coutts-van Dijk LC, Bray JH, Moore S, et al. Prospective study of how students' humanism and psychosocial beliefs relate to specialty matching. Acad Med 1997;72:1106-8.

30. Mann K, Gordon J, MacLeod A. Reflection and reflective practice in health professions education: a systematic review. Adv Health Sci Educ Theory Pract 2009;14:595-621.

31. Oandasan I, Reeves S. Key elements of interprofessional education. Part 2: factors, processes and outcomes. J Interprof Care 2005;19:39-48.

32. Passi V, Johnson S, Peile E, et al. Doctor role modelling in medical education: BEME Guide No. 27. Med Teach 2013;35:e1422-36.

33. Hall P. Interprofessional teamwork: professional cultures as barriers. J Interprof Care 2005;19:188-96.

34. Benbassat J. Role modeling in medical education: the importance of a reflective imitation. Acad Med 2014;89:550-4.

35. Liedtka JM, Whitten E. Enhancing care delivery through crossdisciplinary collaboration: a case study. J Healthc Manag 1998;43:185-205.

36. Rees CE, Crampton P, Kent F, et al. Understanding students' and clinicians' experiences of informal interprofessional workplace learning: an Australian qualitative study. BMJ Open 2018;8:e021238.

37. Schneider DJ. The psychology of stereotyping. New York: Guilford Press, 2004.

38. Rosenbaum ME. Dis-integration of communication in healthcare education: workplace learning challenges and opportunities. Patient Educ Couns 2017;100:2054-61.

39. Cruess RL, Cruess SR, Boudreau JD, et al. A schematic representation of the professional identity formation and socialization of medical students and residents: a guide for medical educators. Acad Med 2015;90:718-25.

40. Jarvis-Selinger S, Pratt DD, Regehr G. Competency is not enough: integrating identity formation into the medical education discourse. Acad Med 2012;87:1185-90. 